\title{
ESTIMATION OF TOTAL FLAVONOID, PHENOLIC CONTENT, AND FREE RADICAL SCAVENGING POTENTIAL OF GLYCYRRHIZA GLABRA ROOT EXTRACT
}

\author{
VELVIZHI S*, ANNAPURANI S \\ Department of Biochemistry, Biotechnology and Bioinformatics, Avinashilingam Institute for Home Science and Higher Education for \\ Women, Coimbatore - 641 043, Tamil Nadu, India. Email: sri.velvizhi@gmail.com
}

Received: 17 November 2017, Revised and Accepted: 21 December 2017

\section{ABSTRACT}

Objective: The present study attempts to estimate the total flavonoid and phenolic content and to evaluate the free radical scavenging activity of the roots of Glycyrrhiza glabra Leguminosae family.

Methods: The various extracts, namely, petroleum ether, chloroform, ethyl acetate, aqueous, and methanol of $G$. glabra root were evaluated by 2, 2-diphenyl-1-picryl-hydrazyl (DPPH), hydroxyl radicals, superoxide, 2,2'-azino-bis-3-ethyl benzthiazoline-6-sulphonic acid (ABTS), and nonradicals such as hydrogen peroxide $\left(\mathrm{H}_{2} \mathrm{O}_{2}\right)$ and nitric oxide (NO) and assays. Total flavonoid and phenol contents were estimated as per the standard procedure.

Results: The effect of the methanolic extract of $G$. glabra root was found to be more in scavenging the free radicals such as DPPH, hydroxyl, $\mathrm{H}_{2} \mathrm{O}_{2}$, superoxide, NO, and ABTS when compared to other extracts. The presence of flavonoids and phenol in the plant is responsible for the free radical scavenging effects.

Conclusion: This in vitro assessment of the antioxidant properties of the various extracts of G. glabra roots validates and confirms its free-radical scavenging activity. Thus, the present data suggest that the G. glabra root extract can be used as a good source of natural antioxidants for health benefits.

Keywords: Glycyrrhiza glabra, 2, 2-diphenyl-1-picryl-hydrazyl, 2,2'-azino-bis-3-ethyl benzthiazoline-6-sulfonic acid, Superoxide, hydroxyl, Hydrogen peroxide, Nitric oxide, Flavonoids, Phenol.

(C) 2018 The Authors. Published by Innovare Academic Sciences Pvt Ltd. This is an open access article under the CC BY license (http://creativecommons. org/licenses/by/4. 0/) DOI: http://dx.doi.org/10.22159/ajpcr.2018.v11i4.23711

\section{INTRODUCTION}

Glycyrrhiza glabra Linn. is one of the most extensively used medicinal herbs from the ancient medical history of Ayurveda. It is also used as a flavoring herb. The word Glycyrrhiza is derived from the Greek term glykos (meaning sweet) and rhiza (meaning root) [1]. This plant is a tall perennial herb, up to $2 \mathrm{~m}$ high found cultivated in Europe, Persia, Afghanistan, and too little extent in some parts of India [2].

Glycyrrhiza plays important parts in Hindu medicine and is one of the principle drugs of the "susruta." In ancient Egypt, Greece, and Rome, Glycyrrhiza was also frequently used. Liquorice is referred by Theophrastus. It is interesting to find that even to this day liquorice is maintaining its place in medicine and pharmacy [3].

It is popularlyused worldwide in food, confectionery, and pharmaceutical products, such as cough syrups, herbal supplements, chewing gums, drinks, and candies. Liquorice roots are extensively used in herbal medicines for their emollient, anti-inflammatory, antiviral, anti-allergic, gastroprotective, and anticancerous properties attributed mainly to the presence of wide range of flavonoids. Various antioxidant properties of G. glabra roots have also been reported which are attributed to the phenolic compounds such as glabridin, licoisoflavone B, licochalcone, and liquirtigenin [4].

Reactive oxygen species (ROS) are continuously produced by the body's normal use of oxygen such as respiration and some cell-mediated immune functions. ROS includes free radicals such as $02 \cdot-$, hydroxyl radicals $(\mathrm{OH} \cdot)$, and non-free-radical species such as hydrogen peroxide $\left(\mathrm{H}_{2} \mathrm{O}_{2}\right)$ and singlet oxygen $\left({ }^{1} \mathrm{O}_{2}\right)[5]$.
Antioxidants can protect the human body from free radicals and ROS effects. They retard the progress of many chronic diseases as well as lipid peroxidation. Novel natural antioxidants from some plants have been extensively studied in the past few years for their antioxidant and radical scavenging properties [6]. Hence, a need for identifying alternative natural and safe sources of food antioxidants has been created, and the search for natural antioxidants, especially of plant origin, has notably increased in recent years. The objective of this study was to estimate the total phenol and flavonoid content and to investigate the free radical scavenging activity of the different extract of G. glabra root sample.

\section{METHODS}

\section{Collection and extraction of plant materials}

G. glabra plants were collected from Tami Nadu Agricultural University and authenticated by Taxonomist from Botanical Survey of India. The plant roots were shade-dried at room temperature and then ground into powder. The sample was extracted into solvents of increasing polarity using a Soxhlet apparatus. About $20 \mathrm{~g}$ of each powdered sample was extracted with $250 \mathrm{~mL}$ of respective solvents such as petroleum ether (PE), chloroform (CH), ethyl acetate (EA), and methanol (ME). The extracts were filtered and concentrated in rotary evaporator to obtain crude extracts. They were stored at $-20^{\circ} \mathrm{C}$ until use. Apart from the solvent extracts, a fresh aqueous extract (AQ) was also prepared. The AQ extract was prepared in distilled water and centrifuged at $2000 \mathrm{rpm}$ for $5 \mathrm{~min}$, and the supernatant was used for the further assay. In the present study, $10-100 \mu \mathrm{g} / \mathrm{ml}$ of the PE, CH, EA, ME, and AQ extracts roots of $G$. glabra were used for the in vitro free radical scavenging activity. Ascorbic acid was used as a standard. 


\section{Estimation of total phenol and flavonoid content}

\section{Estimation of total phenol}

Phenolic compounds are a class of antioxidant agents which act as free radical terminators. The amount of total phenol present in the roots of G. glabra was estimated by the method described by Baba and Malik, 2015 [7].

The Folin-Ciocalteu reagent was used for determining the TPC. Using $100,200,300,400$, and $500 \mu \mathrm{g} / \mathrm{ml}$ concentrations of gallic acid, a standard calibration plot was generated at $760 \mathrm{~nm}$. The concentrations of phenol in the test samples were calculated from the calibration plot. Total phenolic content was expressed as mg gallic acid equivalents (GAE). All determinations were performed in triplicates, and the results were expressed as mg GAE/g sample extract.

\section{Estimation of flavonoids}

Flavonoids are the most common group of polyphenolic compounds in the human diet and are found ubiquitously in plants. Flavonoids are known to be antimutagenic, anticarcinogenic, anti-inflammatory, and anti-allergic with antioxidant properties. A standard calibration plot was generated at $415 \mathrm{~nm}$ using different and known concentrations of quercetin.

The concentrations of flavonoid in the test samples were calculated from the calibration plot and expressed as mg quercetin equivalent/g of sample. The flavonoid content in different parts of the plant was assessed by the method of Chang et al. [8].

\section{Determination of the free radical scavenging activities}

The in vitro free radical scavenging activities of different extracts of G. glabra were evaluated by 2, 2-diphenyl-1-picryl-hydrazyl (DPPH), hydroxyl, $\mathrm{H}_{2} \mathrm{O}_{2}$, superoxide, nitric oxide (NO), and 2,2'-azino-bis-3-ethyl benzthiazoline-6-sulphonic acid (ABTS) assays.

\section{DPPH radical scavenging assay}

DPPH free radical method is an antioxidant assay based on electron transfer that produces a violet solution in ethanol. This free radical, stable at room temperature, is reduced in the presence of an antioxidant molecule, giving rise to colorless ethanol solution. DPPH radical scavenging activity was measured according to the method of Mensor et al. [9].

\section{Hydroxyl radical scavenging assay}

Hydroxyl radical is one of the potent ROS in biological system. It reacts with polyunsaturated fatty acid and causes damage to the cell. The hydroxyl radical scavenging activity was measured in terms of the amount of thiobarbituric acid reactive substances (TBARS) formed on reaction of deoxyribose with $\mathrm{H}_{2} \mathrm{O}_{2}$. The amount of TBARS formed is indirectly proportional to the hydroxyl radical scavenging. The scavenging ability of hydroxyl radicals is measured by the method of Elizabeth and Rao [10].

\section{$\mathrm{H}_{2} \mathrm{O}_{2}$ scavenging assay}

$\mathrm{H}_{2} \mathrm{O}_{2}$ itself is not only very reactive but also could be toxic to cells. The $\mathrm{H}_{2} \mathrm{O}_{2}$ scavenging activity was determined according to the method described by Ruch et al. [11].

\section{Superoxide radical scavenging assay}

Superoxide anion radical is generated by four-electron reduction of molecular oxygen into water. This radical is also formed in aerobic cells due to electron leakage from electron transport chain. In living organisms, superoxide is removed by superoxide dismutase. Superoxide radical scavenging activity of various extracts of $G$. glabra was determined by the method of Misra and Fridovich [12].

\section{NO scavenging assay}

NO produced at the cellular level from L-arginine catalyzed by NO synthase is a very important signaling molecule. NO scavenging activity of various extracts of $G$. glabra roots was determined by the method described by Green et al. [13].

\section{ABTS radical scavenging assay}

The ABTS is the simple, fast, reliable, inexpensive method to assess the total antioxidant capacity of the medicinal herb extracts on a large scale, which is also very adaptable to both hydrophilic and lipophilic antioxidant systems. This effective and efficient method could be used for systematic screening of medicinal herbs and edible plants for their relative antioxidant content. The ABTS radical scavenging activity was determined by the method described by Shirwaiker et al. [14].

\section{RESULTS}

The total flavonoid content (TFC) and TPC were calculated from the absorbance calibration curve generated with different concentrations of quercetin and gallic acid (standards), respectively, which is shown in Fig. 1.

\section{DPPH radical scavenging assay}

DPPH scavenging activity is one of the best methods to screen the free radical scavenging activity of medicinal plants and its compounds. DPPH is scavenged by antioxidants by donating hydrogen ion and forming reduced DPPH. As a result of the formation of reduced DPPH, the color changes from purple to yellow and the intensity of the color increases with increasing percentage of the radical inhibition [15].

DPPH is a free radical that keeps its stability in AQ or methanolic solutions. It accepts an electron or hydrogen ion to become a stable diamagnetic molecule. The percent DPPH scavenging ability by the G. glabra root extract was carried out spectrophotometrically, and the results are presented in Fig. 2.

DPPH radical scavenging activity was found to be increased with increasing concentration of the root extract. At a concentration of $64 \mu \mathrm{g} / \mathrm{ml}$, the methanolic extract of G. glabra recorded $50 \%$ of

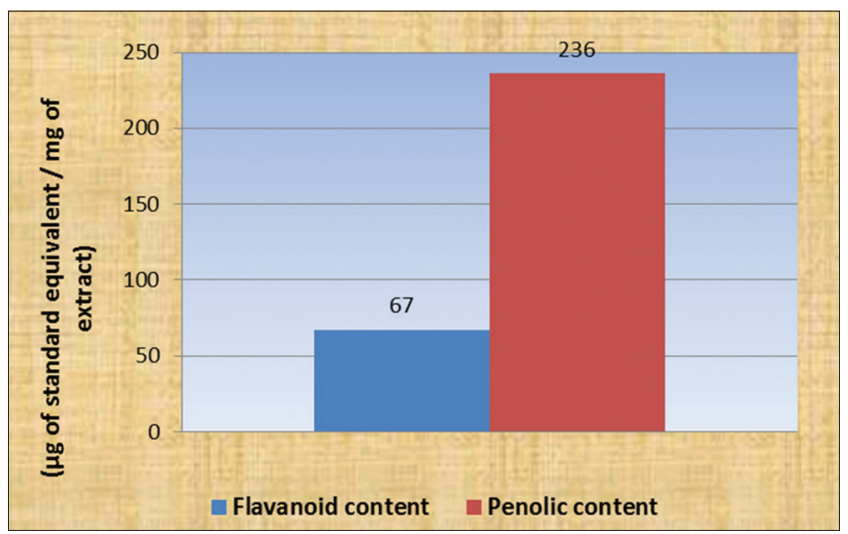

Fig. 1: Estimation of total flavonoid and total phenol content

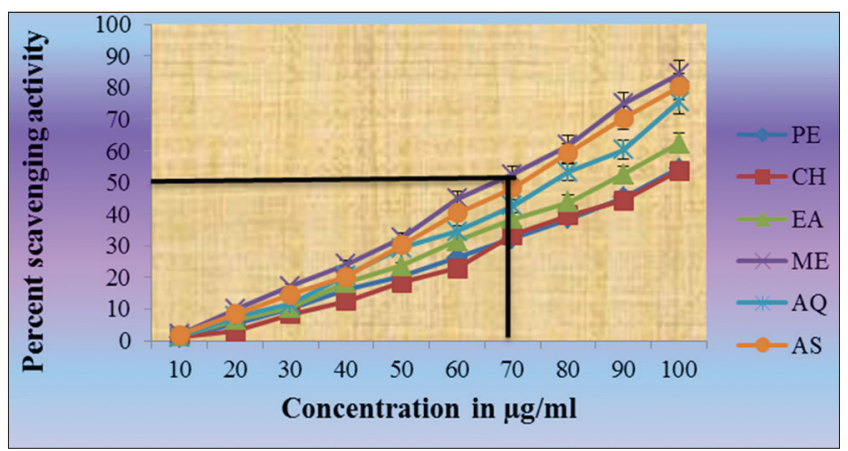

Fig. 2: 2, 2-diphenyl-1-picryl-hydrazyl radical scavenging activity of the Glycyrrhiza glabra root extract of various solvents 
scavenging activity and it is increased to $80 \%$ at a concentration of $100 \mu \mathrm{g} / \mathrm{ml}$. The least scavenging activity was found in $\mathrm{CH}$ extract of roots of the plant assessed.

\section{Hydroxyl radical scavenging assay}

Hydroxyl radicals are the most reactive free radical formed during the metabolism among the ROS which could be formed by superoxide and $\mathrm{H}_{2} \mathrm{O}_{2}$ radicals in the presence of metal ions such as copper or iron [16]. Hydroxyl radical is capable of damaging almost every molecule found in living cells. This radical has the capacity to induce carcinogenesis and rapidly initiate lipid peroxidation [17]. The percent inhibition of hydroxyl radical by various extracts was concentration dependent, and the methanolic extract of G. glabra proved to be more effective than the standard ascorbic acid in scavenging hydroxyl radical which is shown in the Fig. 3.

\section{$\mathrm{H}_{2} \mathrm{O}_{2}$ radical scavenging assay}

$\mathrm{H}_{2} \mathrm{O}_{2}$ exposure significantly increased the TBARS formation, which was effectively counteracted by the presence of the G. glabra root extracts. The $\mathrm{IC}_{50}$ value of methanolic extract was $68 \mu \mathrm{g} / \mathrm{ml}$. All the other solvent extracts also showed good $\mathrm{H}_{2} \mathrm{O}_{2}$ scavenging activity. $\mathrm{H}_{2} \mathrm{O}_{2}$ radical scavenging activity of various solvent extracts was shown in Fig. 4.

\section{Inhibition of superoxide radical generation}

Superoxide is a highly toxic species and can be generated by numerous biological and photochemical reactions. Both aerobic and anaerobic organisms possess superoxide dismutase enzyme which catalyzes the breakdown of superoxide radical [18]. It was found that the methanolic extracts of G. glabra showed the highest inhibitory activity when compared with other extracts at $100 \mu \mathrm{g} / \mathrm{ml}$ concentration. The superoxide radical scavenging activity of all the extracts was found to be concentration dependent, i.e. as the concentration of the extracts increased the radical scavenging activity was also found to be increased. Superoxide generation inhibitory potentials of G. glabra were shown in Fig. 5.

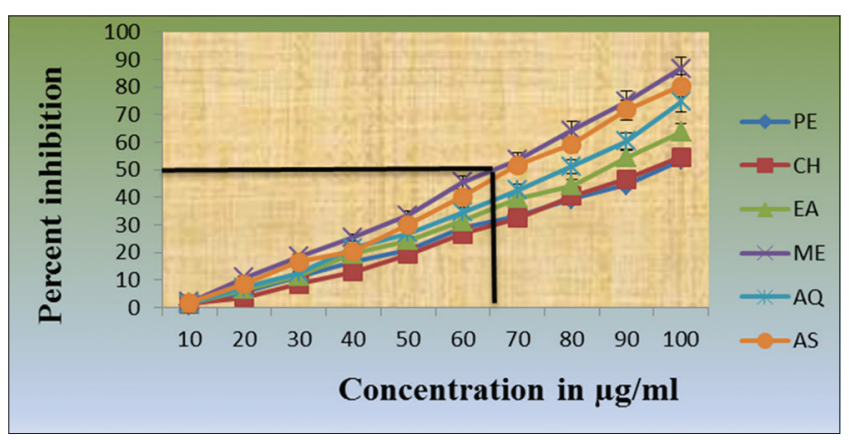

Fig. 3: Hydroxyl radical scavenging effect of the Glycyrrhiza glabra root extract of various solvents

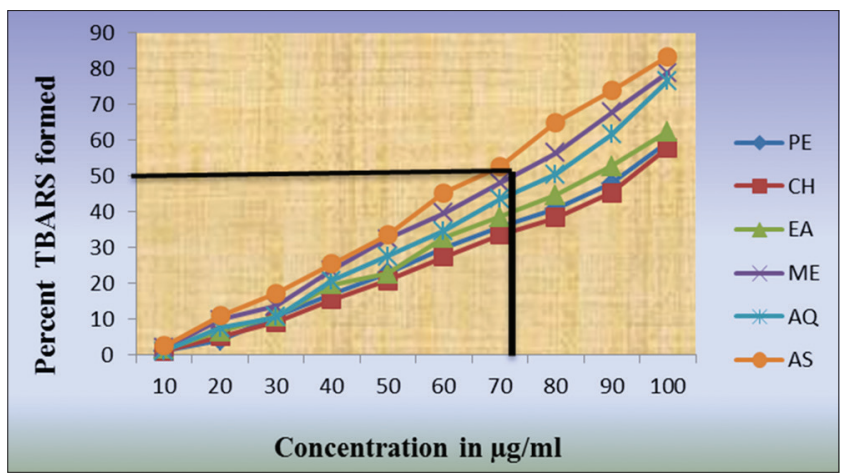

Fig. 4: Hydrogen peroxide radical scavenging effect of Glycyrrhiza glabra root extract of various solvent
Inhibition of NO radical generation

NO is a potent pleiotropic mediator of physiological process such as smooth muscle relaxation, neuronal signaling inhibition of platelet aggregation, and regulation of cell-mediated toxicity [19]. An excess amount of NO may lead to tissue damage and cause various degenerative diseases, namely, cancer, diabetes mellitus, multiple sclerosis, arthritis, and ulcerative colitis. It is also a potent inhibitor of physiological processes such as smooth muscle relaxation, neural signaling, inhibition of platelet aggregation, and regulation of cellmediated toxicity [20]. All the extracts of G. glabra root extract effectively reduced the generation of NO from sodium nitroprusside. Standard ascorbic acid and methanolic extract showed highest NO radical inhibition compared to other solvent extracts. The $\mathrm{IC}_{50}$ value of methanolic extract was $58 \mu \mathrm{g} / \mathrm{ml}$. The effect of the inhibition of the generation of the NO radical potentials of the G. glabra root extracts of various solvents was depicted in Fig. 6.

\section{ABTS radical scavenging assay}

The maximum extent of ABTS scavenging ability was elicited by the methanolic extract ( $\mathrm{IC}_{50}$ value was found to be $44 \mu \mathrm{g} / \mathrm{ml}$ ) of $G$. glabra roots followed by standard ascorbic acid. The least scavenging activity was found in $\mathrm{CH}$ extract as shown in Fig. 7.

\section{DISCUSSION}

The total phenolic content of the methanolic extract was $236 \mathrm{GAE} / \mathrm{mg}$. Similarly, the TFC was assessed as 67 quercetin equivalents/mg. Flavonoids, including flavones, flavanols, and condensed tannins, are plant secondary metabolites, the antioxidant activity of which depends on the presence of free hydroxyl groups. Plant flavonoids have antioxidant activity in vitro and also act as antioxidants in vivo. Plants rich in secondary metabolites, including phenolic, flavonoids, and carotenoids, have antioxidant activity due to their redox properties and chemical structures [21]. An earlier study reported that phenolic compounds are a major source of natural antioxidants in foods of plant origin which in turn exhibit a wide spectrum of biochemical

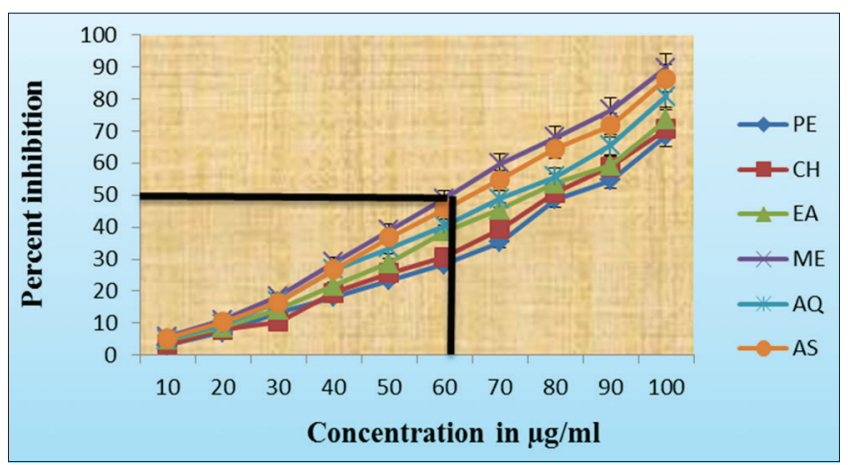

Fig. 5: Inhibition of the generation of the superoxide radical potentials of the Glycyrrhiza glabra root extracts of various solvents

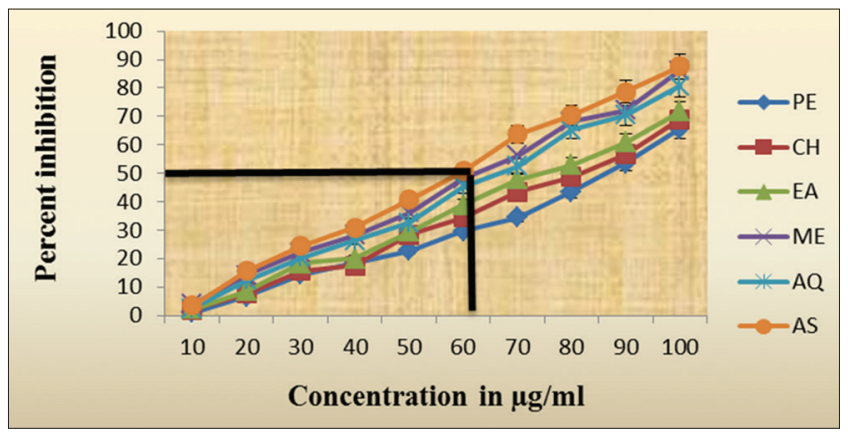

Fig. 6: Effect of the Inhibition of the generation of the nitric oxide radical Glycyrrhiza glabra root extracts of various solvents 


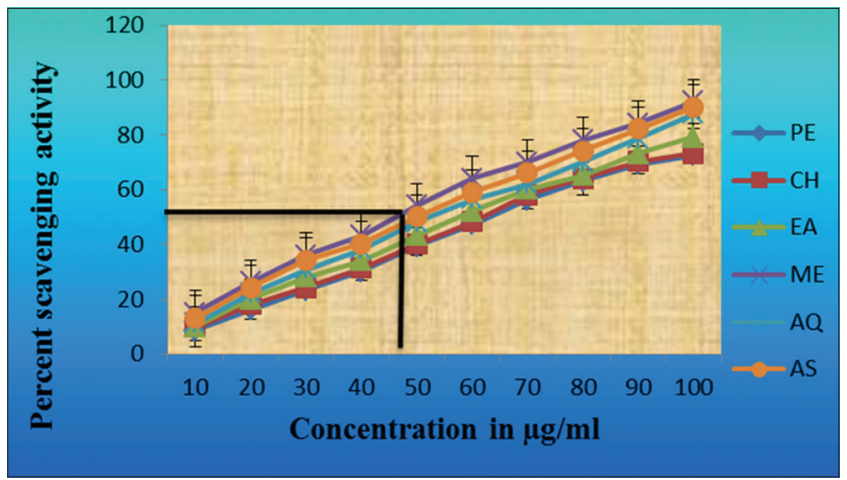

Fig. 7: 2,2'-azino-bis-3-ethyl benzthiazoline-6-sulphonic acid radical scavenging effect of Glycyrrhiza glabra root extract of various solvent extracts

activities such as antimicrobial, antimutagenic, anticarcinogenic as well as the ability to modify the gene expression [22].

Phenolic compounds were produced by plant as a defense mechanism against different stress conditions. Phenolic compounds included flavonoid compounds have various effects such as antioxidant activity, antibacterial activity, antidiabetic, and hepatoprotective [23].

The high phenolic and flavonoid content is responsible for the bioactivity of these crude extracts. Flavonoids are highly effective scavengers of most oxidizing molecules, including singlet oxygen, and various other free radicals implicated in several diseases.

Free radicals are responsible for causing a wide number of health hazards such as cancer, aging, heart diseases, and gastric problems. Oxygen free radicals disintegrate DNA and destroy cell membranes by enzymatic metabolic processes [24].

DPPH is a stable nitrogen-centered free radical commonly used for testing radical scavenging activity of the compound or plant extracts. When the stable DPPH radical accepts an electron from the antioxidant compound, the violet color of the DPPH radical was reduced to yellow-colored diphenyl picrylhydrazine radical which was measured colorimetrically. Substances which are able to perform this reaction can be considered as antioxidants and therefore radical scavengers [25].

Gulcin [5] reported that DPPH radical scavenging activity of G. glabra $\mathrm{AQ}$ and ethanol root extracts was $52.2 \%$ and $54.4 \%$, respectively, at $30 \mu \mathrm{g} / \mathrm{ml}$ concentration. These results support the data reported by Chopra et al. [1] who observed that methanolic extracts of liquorice roots displayed good antioxidant activity $\left(\mathrm{IC}_{50}\right.$ D359.45 mg/mL). AlBachir and Al-Adawi [26] also demonstrated that liquorice roots powder showed antioxidant activity with an $\mathrm{IC}_{50}$ value of $87.152 \mathrm{mg} / \mathrm{mL}$ versus $22.78 \mathrm{mg} / \mathrm{mL}$ for ascorbic acid. The reduction in the DPPH molecule can be correlated with the available number of hydroxyl groups present in the extracts, and it might be due to their hydrogen-donating ability. The high content of phenolic component in methanolic extract of liquorice (G. glabra L.) is responsible for its powerful antioxidant activity by means of significant free radical scavenging, hydrogen-donating, metal ion chelating, and anti-lipid peroxidative and reducing abilities [27].

Glycyrrhizin present in the roots of G. glabra is considered as quenching agent of free radicals and also as blocking agent of lipid peroxidation chain reactions. Glycyrrhizin showed chemopreventive, antioxidant, and anti-proliferative activity when tested on animal model [28].

Liquorice flavonoids have exceptionally strong antioxidant activity. Antioxidant activity of liquorice flavonoids was found to be over 100 times stronger than that of antioxidant activity of Vitamin E. A dose of $2.58 \mathrm{mg} / \mathrm{ml}$ liquorice flavonoids can scavenge more free radicals (20.6\% scavenging) than $258 \mathrm{mg} / \mathrm{ml}$ of Vitamin E $(11.2 \%$ scavenging). The flavonoids from liquorice are currently the strongest natural antioxidants known [29]. The isoflavones, glabridin and hispaglabridins A and B, have considerable antioxidant activity. Both glabridin and glabrene have estrogen-like activity [30]. A previous study reported by Franceschelli [31] evidenced that the constituents of G. glabra were effective in preventing microsomal lipid peroxidation and licochalcone $\mathrm{B}$ and $\mathrm{D}$ exhibited potent antioxidative and superoxide scavenging activities. Barik et al. [19] demonstrated that the NO scavenging activity of AQ and ethanolic extract of G. glabra was found to be in the range of $20.63 \%$ which is similar to the findings of the present study. Kang et al. [32] demonstrated that glabridin a polyphenolic compound present in G. glabra inhibits NO production. There was a concentration-dependent inhibition against hydroxyl radical exhibited by G. glabra ethanolic extract and was in the range of 35.1\% [33]. The percent scavenging of ABTS and $\mathrm{H}_{2} \mathrm{O}_{2}$ radicals was also dose dependent indicating that the root sample exhibited maximum radical scavenging activity which was supported by Mradu Gupta et al. [34]. The percentage inhibition as well as the low $\mathrm{IC}_{50}$ values of DPPH, hydroxyl, superoxide, $\mathrm{H}_{2} \mathrm{O}_{2}, \mathrm{NO}$, and ABTS assay of standard ascorbic acid and methanolic extract indicates that its very high antioxidant capacity in comparison with other solvent extract.

\section{CONCLUSION}

The evaluation of the free radical scavenging activity of various extracts of G. glabra showed substantial and significant free radical scavenging activity during the study which is comparable to that of the standard drug. The methanolic extract exhibits a higher level of activity than the other extracts in all the antioxidant assessment. This significant pronounced antioxidant activity of G. glabra roots may be due to the presence of higher concentrations of flavonoids and phenols in the plant sample. This in vitro assessment of the antioxidant properties of the methanolic extracts of G. glabra validates and confirms its free-radical scavenging activity. Thus, the present data suggest that the G. glabra root extract can be used as a good source of natural antioxidants for health benefits.

\section{AUTHORS CONTRIBUTIONS}

Annapurani S designed the experimental study and Velvizhi S carried out analysis and coordinated in preparing the manuscript and revision. Both the authors have read and approved the final manuscript.

\section{CONFLICTS OF INTERESTS}

All authors have none to declare.

\section{REFERENCES}

1. Chopra PK, Saraf BD, Inam F. Antimicrobial and antioxidant activities of methanol extract roots of Glycyrrhiza glabra and HPLC analysis. Int J Pharm Pharmacol Sci 2013;5:157-60.

2. Visavadia NP, Soni B, Dalwadi N. Evaluation of anti-oxidant and anti atherogenic properties of Glycyrrhiza glabra roots using in vitro models. Int J Food Sci Nutr 2009;60:135-49.

3. Singh G, Gupta A, Jjalhan S, Jindal A. Pharmacological activities on Glycyrrhiza glabra -a review. Asian J Pharm Clin Res 2013;11:5-7.

4. Govt. of India, Ministry of Health and Family Welfare. Ayurvedic Pharmacopoeia of India Part-I. Vol. 1. New Delhi: Govt. of India, Ministry of Health and Family Welfare; 168-9.

5. Gulcin I. Antioxidant activity of L-Adrenaline: An activity-structure insight. Chem Biol Interact 2009;179:71-80.

6. Sangameswaran B, Chubhale D, Balakrishnan BR, Jayakar B. Hepatoprotective effects of Thespesia lampas. Dhaka Univ J Pharm Sci 2008;7:11-3

7. Baba SA, Malik SA. Determination of total phenolic and flavonoid content, antimicrobial and antioxidant activity of a root extract of Arisaema jacquemontii. J Taibah Univ Sci 2015;9:449-54.

8. Chang C, Yang M, Wen H. Estimation of total flavonoid content in propolis by two complementary colorimetric methods. J Food Drug Anal 2002;10:178-82.

9. Mensor LI, Menezes FS, Leitao GG, Reis AS, Santos DT, Coube CS, Leitao SG. Screening of Brazilian plant extracts for antioxidant activity 
by the use of DPPH free radical method. Phyto Res 2001;15:127-30.

10. Elizabeth K, Rao MN. Oxygen radical scavenging activity of Curcumin. Int J Pharm 1990;58:237-40.

11. Ruch RJ, Cheng SJ, Kalaunig JE. Prevention of cytotoxicity and inhibition of intracellular communication by antioxidant catechins isolated from Chinese green tea. Carcinogenesis 1989;10:1003-8.

12. Misra MP, Fridovich I. The role of superoxide anion in the auto oxidation of epinephrine and simple assay for superoxide dismutase. J Biol Chem 1972;247:3170-5

13. Green LC, Wagner DA, Gloowski J, Skipper PL, Wishnok JS, Tannenbaum SR. Analysis of nitrate, nitrite and $(15 \mathrm{~N})$ nitrate in biological fluids. Anal Biochem 1982;126:131-6.

14. Shirwaikar A, Shirwaikar A, Rajendran K, Punitha IS. In vitro antioxidant studies on the benzyl tetra isoquinoline alkaloid berberine. Biol Pharm Bull 2006;29:1906-10.

15. Shivakumar S, Sandhiya S, Subhasree N. Agrawal A, Dubey GP. In vitro assessment of antibacterial and antioxidant activities of fruit rind extracts of Garcinia cambogia L. Int J Pharm Pharm Sci 2013;5:254-57.

16. Dhal Y, Deo B, Sahu RK. Comparative antioxidant activity of nonenzymatic and enzymatic extracts of Curcuma zedoaria, Curcuma angustifolia and Curcuma caesia, Int J Plant Anim Environ Sci 2012;2:232-9.

17. Manian R, Anusuya N, Siddhuraju P, Manian S. The antioxidant activity and free radical scavenging potential of two different solvent extracts of Camellia sinensis (L.) Ficus bengalensis L. and Ficus racemosa L. Food Chem 2008;107:1000-7.

18. Kowti R, Hareesh AR, Harsha R. In vitro free radical scavenging activity of leaves of Spathodea campanulata. Int J Drug Dev Res 2010;2:622-8.

19. Barik CS, Kanungo SK, Tripathy NK, Panda J, Sahoo B. Evaluation of free radical scavenging activity of poly herbal formulations containing four different plant extracts. Der Pharm Lett 2016;8:496-501.

20. Sahoo S, Ghosh G, Das D, Nayak S. Phytochemical investigation and in vitro antioxidant activity of an indigenous medicinal plant Alpinia nigra BL. Burtt. Asian Pac J Trop Biomed 2013;3:871-6.

21. Geetha S, Sai Ram M, Mongia SS, Singh V, Ilavazhagan G, Sawhney RC, et al. Evaluation of antioxidant activity of leaf extract of Seabuckthorn (Hippophae rhamnoides L.) on chromium(VI) induced oxidative stress in albino rats. J Ethnopharmacol 2003;87:247-51.

22. Sunila AV, Murugan K. Variation in phenolics, flavonoids at different stages of fruit development of Pouteria campechiana(kunth) baehniand its antioxidant activity. Int J Pharm Pharm Sci 2017;9:70-5.
23. Fidrianny I, Fitrani D, Kusmardiyani S, Rizaldy D, Ruslan K. In vitro antioxidant and phytochemical analysis of different parts of simana lagi apple (Malus, Domestica borkh.] "simana lagi") grown in east javaIndonesia. Asian J Pharm Clin Res 2017;10:41-5.

24. Rajpurohit A, Nayak DS, Patil S, Mahadevan KM. In vitro antioxidant, antimicrobial and admet study of novel furan/ benzofuran c-2 coupled quinoline hybrids. Int J Pharm Pharm Sci 2017; 19:144-53.

25. Dehpour AA, Ebrahimzadeh MA, Nabavi SF, Nabavi SM. Antioxidant activity of methanol extract of Ferula assafoetida and its essential oil composition. Grasas Aceites 2009;60:405-12.

26. Al-Bachir M, Al-Adawi M. Comparative effect of irradiation and heating on the microbiological properties of licorice (Glycyrrhiza glabra L.) root powders. Int J Radiat Biol 2015;91:112-6.

27. Jahan Y, Siddique HH. Study of antitussive potential of Glycyrrhiza glabra and Adhatoda vasica using a cough model induced by $\mathrm{SO}_{2}$ gas in mice. Int J Pharm Sci Res 2012;3:1668-74.

28. Rahman S, Sultana S. Glycyrrhizin exhibits potential chemopreventive activity on 12-O-tetradecanoyl phorbol13-acetate-induced cutaneous oxidative stress and tumor promotion in Swiss albino mice. J Enzyme Inhib Med Chem 2007;22:363-9.

29. Alonso J. Tratado de Fitofármacos Nutracéuticos. Barcelona: Corpus; 2004. p. $905-11$

30. Vaya J, Belinky PA, Aviram M. Antioxidant constituents from licorice roots: Isolation, structure elucidation and antioxidative capacity toward LDL oxidation. Free Radic Biol Med 1997;23:302-13.

31. Franceschelli S, Pesce M, Vinciguerra I, Ferrone A, Riccioni G, Patruno A, et al. Licocalchone-C extracted from Glycyrrhiza glabra inhibits lipopolysaccharide-interferon- $\gamma$ inflammation by improving antioxidant conditions and regulating inducible nitric oxide synthase expression. Molecules 2011;16:5720-34.

32. Kang JS, Yoon YD, Cho IJ, Han MH, Lee CW, Park S, et al. Glabridin, an isoflavan from Licorice root inhibits nitric oxide synthase expression and improve survival of mice in experimental model of septic shock. J Pharm Exp Ther 2004;312:5-33.

33. Anusuya N, Anusuya S, Manian R, Siddhuraju P, Manian S. Antioxidant and free radical scavenging activity of certain dietary and medicinal plant extracts. Food 2009;3:47-52.

34. Gupta M, Karmakar N, Sasmal S, Chowdhury S, Biswas S. Free radical scavenging activity of aqueous and alcoholic extracts of Glycyrrhiza glabra Linn. Measured by ferric reducing antioxidant power (FRAP), ABTS bleaching assay ( $\alpha$ TEAC), DPPH assay and peroxyl radical antioxidant assay. Int J Pharma Toxicol 2016;4:235-40. 